\title{
Correction to: Genome-wide identification of hexokinase gene family in Brassica napus: structure, phylogenetic analysis, expression, and functional characterization
}

Jingxue Wang ${ }^{1} \cdot$ Xiaomin Wang $^{1} \cdot$ Siyu Geng ${ }^{1} \cdot$ Sanjay K. Singh ${ }^{2} \cdot$ Yaohui Wang $^{1} \cdot$ Sitakanta Pattanaik $^{2} \cdot$ Ling Yuan $^{1,2}$

Published online: 21 April 2018

○) Springer-Verlag GmbH Germany, part of Springer Nature 2018

Correction to: Planta

https://doi.org/10.1007/s00425-018-2888-8

In the original version of this article the name of the second author was misspelled. The correct name is: Xiaomin Wang.

The original article has been corrected.

The original article can be found online at https://doi.org/10.1007/ s00425-018-2888-8.

Jingxue Wang

jingxuew@sxu.edu.cn

$\triangle$ Ling Yuan

lyuan3@uky.edu

1 School of Life Sciences, Shanxi University, Taiyuan 030006,

Shanxi, China

2 Department of Plant and Soil Sciences, Kentucky Tobacco

Research and Development Center, University of Kentucky,

Lexington, KY 40546, USA 